\title{
Forced Degradation Studies for Estimation of Finerenone by RP-HPLC Method
}

\section{Arulselvan Murugesan ${ }^{1 *}$ and Annapurna Mukthinuthalapati Mathrusri $^{2}$}

${ }^{1}$ Department of Pharmaceutical Analysis, AIKTC School of Pharmacy, India

${ }^{2}$ Department of Pharmaceutical Analysis and Quality Assurance, GITAM Institute of

Pharmacy, GITAM (Deemed to be University), Visakhapatnam, India

*Corresponding Author: Arulselvan Murugesan, Department of Pharmaceutical

Analysis, AIKTC School of Pharmacy, India.
Received: September 21, 2021

Published: November 12, 2021

(C) All rights are reserved by Arulselvan

Murugesan and Annapurna

Mukthinuthalapati Mathrusri.

\begin{abstract}
Finerenone is a mineralocorticoid receptor antagonist approved by USFDA for the treatment of chronic kidney diseases (CKD) progression in Type 2 Diabetic Mellitus (T2DM) patients. It reduces the sustained risk of GFR and other risks associated with T2DM. This work involved developing first of its kind simple, precise and stability indicating method for analyzing Finerenone by RP-HPLC. The assay was carried out in HPLC X-bridge C18 Column, $150 \mathrm{~mm}$ x $4.6 \mathrm{~mm}, 3.5 \mu \mathrm{m}$, using mobile phase Acetonitrile and OrthoPhosphoric acid (70:30\% v/v) at a flow rate of $1 \mathrm{~mL} / \mathrm{min}$. The analyte was detected by using UV detector at a wavelength of $225 \mathrm{~nm}$. The proposed method validation as per ICH guidelines and showed that the proposed method is highly sensitive, accurate, precise, robust, linear and stability indicating. The linear regression value was found to be greater than 0.9999 with $Y=261640 \mathrm{x}+32993$ and $\mathrm{r}^{2}=0.9999$ with the concentration range of $1 \mu \mathrm{g} / \mathrm{mL}$ to $50 \mu \mathrm{g} / \mathrm{mL}$. Good amount of recovery (100.3\%, 100.4 and 100.6\%) acceptable closeness of agreement ( 0.74 and 0.11 ) observed for Recovery and Intermediate and Method Precision studies conducted by this developed method. Stress degradation study reveals notable degradation within the official guideline values provided by ICH.
\end{abstract}

Keywords: Chronic Kidney Disease; Finerenone; T2DM; Mineralocorticoid; GFR

\section{Introduction}

Finerenone is chemically called as (S)-4-(3-cyano5-methoxyphenyl)-5-ethoxy-2, 8-dimethyl-1, 4-dihydro-1, 6-naphthyridine-3-carboxamide. Finerenone (BAY94-8862) is a novel nonsteroidal MRA with more potential than spironolactone and greater affinity than eplerenone in vitro [1,2]. Finerenone structural activity has a strong binding mode within Mineralocorticoid Receptor MR [3], as well as physicochemical properties like lipophilicity and polarity, which govern plasma protein binding, transport, tissue penetration and distribution [4]. Finerenone treatment prevents functional and structural damage in kidney and heart from deoxycorticosterone acetate (DOCA) than other equinatriuretic doses [5].
Currently, there is no report regarding assay and degradation of Finerenone by RP-HPLC as per our knowledge but, very few articles reported by various other analytical methods for estimation of this drug in Bioanalytical studies [6]. The major focus of this research work was to estimate the drug finerenone with RP-HPLC method as per the official ICH guidelines [7].

This developed study was found to the first reported study of stability indicating validation method as per the ICH guidelines [8-11]. Hence, this developed method employed in studying the degraded products of Finerenone and its assay estimation. The research products of Finerenone received from Zydus Cadila Pharmaceuticals, Gujarat. 
<smiles>CCOc1ncc(C)c2c1C(C1C(C#N)=C(C)Nc3cc(OC)cc1c3)C(C(N)=O)=C2C</smiles>

Figure 1: Chemical structure of Finerenone.

\section{Experimental}

\section{Materials and reagents}

Finerenone was received as a gift sample from Zydus Cadila Pharmaceuticals, Gujarat. Analytical reagent grade acetonitrile, orthophosphoric acids were purchased from Rankem Limited, India. Double distilled water filter through $0.45 \mu$ used for this study. Finerenone working standard received from Zydus Cadila, Gujarat, India.

\section{Instrumentation and optimized conditions}

Fully automated HPLC system manufactured by Waters was used for method development, validation and stress degradation study. This RP HPLC system consisted of a quaternary pump, auto sampler, column oven and a PDA Detector. Empower2 has been used as a data acquisition program to procure and process all chromatographic data of this study. The chromatographic separation for Finerenone was achieved on an X-bridge C18 Column, $150 \mathrm{~mm}$ x $4.6 \mathrm{~mm}, 3.5 \mu \mathrm{m}$, using mobile phase Acetonitrile and Ortho-Phosphoric acid $(70: 30 \% \mathrm{v} / \mathrm{v})$ at a flow rate of $1 \mathrm{ml} / \mathrm{min}$. The analyte was detected by using a PDDA detector at a wavelength of $225 \mathrm{~nm}$. The mobile phase filtered using $0.45 \mu \mathrm{m}$ prior to use. The column was maintained at ambient temperature $\left(25^{\circ} \mathrm{C}\right)$ and an injection volume of $10 \mu \mathrm{L}$ was injected into the system during each study.

\section{Preparation of stock solution}

Standard stock solution of Finerenone was prepared by transferring and dissolving $10 \mathrm{mg}$ of finerenone into $100 \mathrm{ml}$ volumetric flask. The mobile phase was added into it and then sonicated for $20 \mathrm{~min}$ to dissolve analyte. Solutions for further experiments were prepared by using mobile phase as per the concentration required for studies.

\section{Preparation of sample solution}

Transferred $54 \mathrm{mg}$ of Finerenone sample (equivalent to $10 \mathrm{mg}$ of Finerenone) into a $100 \mathrm{~mL}$ volumetric flask and added $70 \mathrm{~mL}$ of diluent into it, sonicated to dissolve and made the volume with diluent.

\section{Preparation of buffer}

$1 \mathrm{~mL}$ of OPA was dissolved in $1000 \mathrm{~mL}$ of HPLC grade water and filtered through $0.45 \mu \mathrm{m}$ filter paper.

Preparation of mobile phase

Acetonitrile and Buffer solution was utilized in the ratio of 70:30 by mixing $700 \mathrm{~mL}$ and $300 \mathrm{~mL}$. Degassing of the solvent was done and then sonicated the solvent reservoir containing mobile phase composition for $20 \mathrm{~min}$. The solvent was filtered through $0.45 \mu \mathrm{m}$ membrane filter paper.

\section{Chromatographic condition}

Use a suitable High Performance Liquid Chromatographic equipped with PDA- detector.

- Column: X-bridge $\mathrm{C}_{8}$ column, $150 \mathrm{~mm}$ x $4.6 \mathrm{~mm}, 3.5 \mu \mathrm{m}$.

- Wavelength: $225 \mathrm{~nm}$

- Injection Volume: $10 \mu \mathrm{L}$

- Column Temperature: Ambient

- Flow rate: $1.0 \mathrm{~mL} / \mathrm{min}$

- Sample Temperature: Ambient

- Run time: Ambient

Preparation of diluent

Use Mobile Phase as a diluent.

Method development

A series of different composition mobile phases were studied in order to develop a stability indicating RP-HPLC method for Finerenone. Effective mobile phase composition selected based on specificity, selectivity and sensitivity for the assay method, stability and stress degradation studies. The optimized chromatographic conditions were validated based on various chromatographic data obtained from different validating parameter such as Specificity, Linearity, Accuracy, Precision, Limit of Quantification (LOQ), Limit of Detection (LOD), Robustness, and system suitability methods as per ICH guidelines.

Solution stability was determined by inter-predicting the solution prepared and kept at $25^{\circ} \mathrm{C}$ i.e., laboratory temperature. Solu- 
tion samples are analyzed at different time intervals such as initial, $6 \mathrm{~h}, 12 \mathrm{~h}, 18 \mathrm{~h}$ and $24 \mathrm{~h}$ to assess its stability nature.

For Linearity, standard stock solution of Finerenone was diluted and prepared with concentration range of $1 \mu \mathrm{g}$ to $50 \mu \mathrm{g} / \mathrm{mL}$. LOQ and LOD values determined from the standard deviation of the response and slope as per ICH guidelines. Each concentration set of three solutions prepared and injected to plot a calibration curve considering concentration of finerenone versus its peak area.

LOD and LOQ were determined from the calibration curves plotted in varying concentration ranges of $1 \mu \mathrm{g} / \mathrm{mL}$ to $50 \mu \mathrm{g} / \mathrm{mL}$. Using the formula $\mathrm{LOD}=3.3 \sigma / \mathrm{S}$ and $\mathrm{LOQ}=10 \sigma / \mathrm{S}$, the acceptance criteria value calculated and verified its acceptance level as per the ICH guidelines.

Recovery method was determined by adding known concentration of analyte into the standard solution to spike the concentration into 50,100 and 150\%. Solutions prepared in triplicate and injected to calculate its \% recovery, RSD and Standard deviation values.

Intermediate and Method precision was evaluated by analyzing six different independent samples within a day and on alternate days in different conditions and different instruments. RSD (\%), Standard deviation values were calculated to know the precision of the proposed method.

Deliberate variation of the proposed method was analyzed by altering the optimized chromatographic conditions such as flow rate (altered by $\pm 0.2 \mathrm{~mL} / \mathrm{min}$ ) and detection wavelength (altered by $\pm 2 \mathrm{~nm}$ ).Each conditions, triplicate sample solution injected into the system to measure the RSD and standard deviation error.

\section{Forced degradation studies}

Forced degradation studies conducted to study and ensure the stability of developed methods under different conditions. Finerenone was intentionally exposed to stress conditions such as acidic, basic, oxidative, thermal and photolytic (UV light).

\section{Acidic degradation}

To $1 \mathrm{~mL}(10 \mu \mathrm{g} / \mathrm{ml})$ of diluted stock solution, $9 \mathrm{~mL}$ of $0.1 \mathrm{~N} \mathrm{HCl}$ was added and refluxed in a water bath $\left(60^{\circ} \mathrm{C}\right)$ for $60 \mathrm{~min}$. After $1 \mathrm{~h}$, allow the solution to reach room temperature and then neutralize the solution with $0.1 \mathrm{~N} \mathrm{NaOH}$.

\section{Alkali degradation}

To $1 \mathrm{~mL}(10 \mu \mathrm{g} / \mathrm{mL})$ of diluted stock solution, $9 \mathrm{ml}$ of $0.1 \mathrm{~N}$ $\mathrm{NaOH}$ was added and refluxed in a water bath $\left(60^{\circ} \mathrm{C}\right)$ for $60 \mathrm{~min}$. After $1 \mathrm{~h}$, the solution was allowed to reach room temperature and then neutralized the solution with $0.1 \mathrm{~N} \mathrm{HCl}$.

\section{Oxidation}

$1 \mathrm{~mL}$ of diluted stock solution was transferred into $100 \mathrm{~mL}$ volumetric flask and then added $9 \mathrm{~mL}$ of $30 \%$ Hydrogen peroxide and refluxed it for $4 \mathrm{~h}$ in a water bath $\left(70^{\circ} \mathrm{C}\right)$.

\section{Irradiation with ultraviolet light}

Solid state degradation was conducted by irradiating the 100 mg powder sample of Finerenone under Ultra-violet rays (254 nm) for $24 \mathrm{~h}$. After exposure, the solution was diluted and then injected in triplicate, into the HPLC system.

\section{Thermal degradation}

For thermal degradation study, $100 \mathrm{mg}$ Finerenone powder was kept inside a thermostat oven at $80^{\circ} \mathrm{C}$ conditions for $24 \mathrm{hr}$. The entire stressed samples are diluted to get $10 \mu \mathrm{g} / \mathrm{mL}$ sample solution and then injected into the system. For above stressed conditions triplicate sample solutions were prepared and analyzed immediately after treatment in RP-HPLC.

\section{Results and Discussion}

To optimize the developed stability indicating method, several conditions were adopted to check its efficiency in separation and ability to remain robust. Various mobile phase compositions carried out with different concentration of buffers and Acetonitrile at fixed $\mathrm{pH}$, ambient column temperature and flow rate $1.00 \mathrm{~mL} / \mathrm{min}$.

Ambient temperature separated the analyte with minimal tailing effect and the results found more reproducible and effective. $\mathrm{pH}$ played an important role in separating Finerenone, at $\mathrm{pH} 4$ the analyte got separated with broad peak width and longer retention time. At pH 5 the analyte took time to elute and retain for a long time within the stationary phase, whereas at $\mathrm{pH} 3.5$ the peak width and retention time found to be precise and optimum.

Ortho phosphoric acid pH 3.5 separated effectively the analyte in combination with Acetonitrile in the ratio of $70: 30$ at $25^{\circ} \mathrm{C}$ and flow rate of $1 \mathrm{~mL} / \mathrm{min}$. 


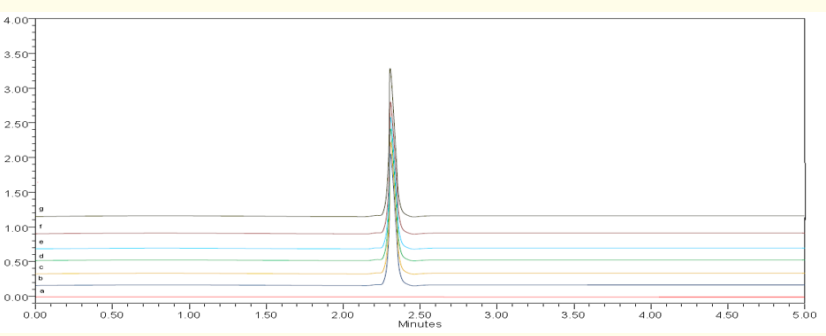

Figure 2: Chromatogram of Finerenone in Optimized Condition.

\section{Method validation}

\section{Linearity}

The plotted calibration curve was found to be linear figure 3 over the concentration range $1-50 \mu \mathrm{g} / \mathrm{mL}$ and the correlation coefficient value obtained was greater than 0.999 figure 4 . Linearity results confirmed the proportional correlation between the concentration and peak area of finerenone.

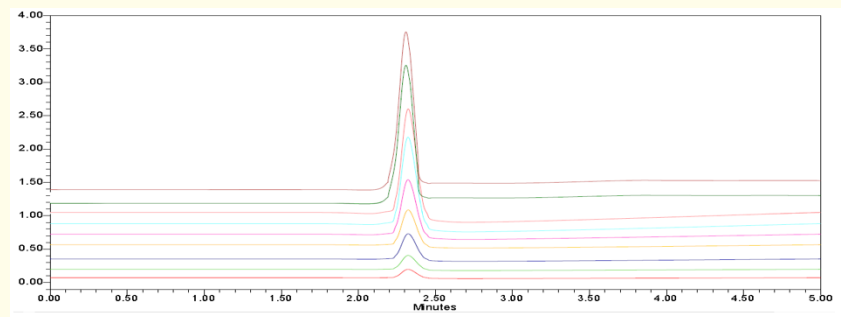

Figure 3: Linearity chromatogram of concentration range of $1-50 \mu \mathrm{g} / \mathrm{mL}$ at $225 \mathrm{~nm}$.

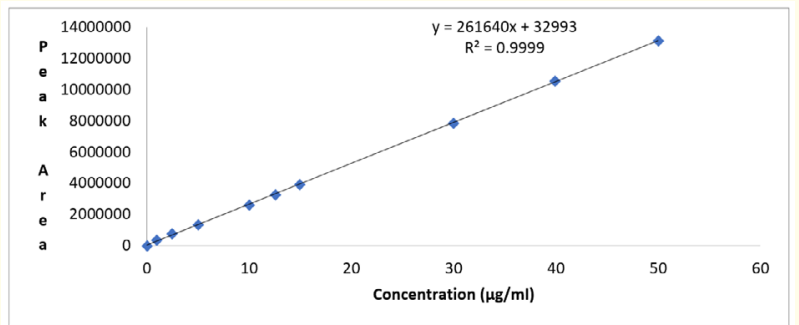

Figure 4: Calibration Curve of Finerenone at $225 \mathrm{~nm}$.

\begin{tabular}{|l|c|c|}
\hline S. No & Conc $(\mu \mathrm{g} / \mathbf{m L})$ & *Mean peak area \pm SD (\% RSD) \\
\hline 1 & 0 & 0 \\
\hline 2 & 1 & 325422.00 \\
\hline 3 & 2.5 & 755020.67 \\
\hline 4 & 5 & 1347679.67 \\
\hline 5 & 10 & 2615789.00 \\
\hline 6 & 12.5 & 3268128.67 \\
\hline 7 & 15 & 3950607.33 \\
\hline 8 & 30 & 7864811.67 \\
\hline 9 & 40 & 10487158.33 \\
\hline 10 & 50 & 13147597.33 \\
\hline & Slope & 261640.294 \\
\hline & Intercept & 32992.586 \\
\hline & Coefficient Correlation & 0.9999 \\
& value & \\
\hline
\end{tabular}

Table 1: Linearity Results.

*Mean of three replicates.

Limit of detection and limit of quantification

The LOD and LOQ for the drug Finerenone was found to be 0.02 and $0.04 \mu \mathrm{g} / \mathrm{mL}$ respectively. The lowest value of LOD and LOQ signifies that our proposed method is more sensitive for estimation of Finerenone drug.

\section{Accuracy}

The percentage recovery of finerenone by the proposed method was found to be $100.4,100.3,100.5 \%$. Finerenone peak area and its $\%$ recovery of $50 \%, 100 \%$ and $150 \%$ summarized in table $2 \mathrm{~A}$.

\section{Precision}

Intermediate and Method precision was evaluated by performing six replicate injections of the working standard of Finerenone. Obtained \% RSD value and its standard deviation error of Intermediate and Method Precision (0.74 and 0.11) remain close to the values of the homogeneous standard and sample analyzed under the prescribed conditions. The analyzed data of finerenone indicates good agreement among the individual test results summarized in table $2 \mathrm{~B}$ and its \% RSD value fulfills the criteria demanded by ICH. 


\begin{tabular}{|l|c|c|c|c|}
\hline Drug & $\begin{array}{c}\text { Spiked Conc } \\
(\mu \mathrm{g} / \mathbf{m l})\end{array}$ & $\begin{array}{c}* \text { mean peak area } \mathbf{S D}(\mathbf{\%} \\
\mathbf{R S D})\end{array}$ & $\begin{array}{c}\text { Drug found } \\
(\boldsymbol{\mu g} / \mathbf{m l})\end{array}$ & \% Recovery \\
\hline \multirow{3}{*}{ Finerenone } & $5(50 \%)$ & $1315638 \pm 10764(0.82)$ & 5.02 & 100.4 \\
\cline { 2 - 5 } & $10(100 \%)$ & $2627109 \pm 8622(0.33)$ & 10.03 & 100.3 \\
\cline { 2 - 5 } & $15(150 \%)$ & $3953122 \pm 11549(0.19)$ & 15.09 & 100.6 \\
\hline
\end{tabular}

Table 2A: Recovery Study of Finerenone.

*Mean of three replicates.

\begin{tabular}{|c|c|c|c|c|c|}
\hline \multirow[t]{2}{*}{ Drug } & \multirow{2}{*}{$\begin{array}{c}\text { Concentration }(\mu \mathrm{g} / \\
\mathrm{mL})\end{array}$} & \multicolumn{2}{|c|}{ Intermediate Precision } & \multicolumn{2}{|c|}{ Method Precision } \\
\hline & & $\begin{array}{c}\text { *Mean peak area } \\
\pm \text { SD }\end{array}$ & \% RSD & $\begin{array}{c}\text { *Mean peak area } \\
\pm \text { SD }\end{array}$ & $\%$ RSD \\
\hline \multirow[t]{2}{*}{ Finerenone } & \multirow{2}{*}{10} & 2625039.00 & \multirow{2}{*}{0.74} & 2619969.00 & \multirow{2}{*}{0.11} \\
\hline & & 19535.00 & & 2867.00 & \\
\hline
\end{tabular}

Table 2B: Precision Study of Finerenone.

*mean of six replicates.

\section{Robustness}

None of the deliberated conditions produce any significant variation among the chromatographic resolution in the developed RP HPLC method for Finerenone. The evaluated values are robust in the different study conditions; hence it can reproduce in any labo- ratory experimental conditions. Analytical chromatogram data obtained for deliberate various experiments performed by the developed method is indicated in table 3 and found to be less than $2 \%$ as per the criteria prescribed.

\begin{tabular}{|c|c|c|c|c|c|}
\hline \multirow[t]{2}{*}{ S. No } & \multirow[b]{2}{*}{ Parameter Condition } & \multicolumn{2}{|r|}{ SAMPLE } & \multicolumn{2}{|c|}{ STANDARD } \\
\hline & & *Mean area & $\begin{array}{c}\text { *Mean peak area } \pm \text { SD } \\
(\% \mathrm{RSD})\end{array}$ & *Mean area & $\begin{array}{c}\text { *Mean peak area } \pm \text { SD } \\
(\% R S D)\end{array}$ \\
\hline \multirow[t]{3}{*}{1} & Flow rate $(0.8 \mathrm{~mL} / \mathrm{min})$ & 2946457 & 2971922 & 2948752 & 2965903 \\
\hline & Flow rate $(0.8 \mathrm{~mL} / \mathrm{min})$ & 2984721 & 22053 & 2974596 & 14854 \\
\hline & Flow rate $(0.8 \mathrm{~mL} / \mathrm{min})$ & 2984587 & 0.74 & 2974362 & 0.50 \\
\hline \multirow[t]{3}{*}{2} & Flow rate $(1.2 \mathrm{~mL} / \mathrm{min})$ & 2218247 & 2221395 & 2217845 & 2217824 \\
\hline & Flow rate $(1.2 \mathrm{~mL} / \mathrm{min})$ & 2224513 & 3133 & 2217325 & 488 \\
\hline & Flow rate $(1.2 \mathrm{~mL} / \mathrm{min})$ & 2221425 & 0.14 & 2218301 & 0.02 \\
\hline \multirow[t]{3}{*}{3} & Mobile Phase (68:32) & 2888241 & 2888969 & 2884721 & 2884302 \\
\hline & Mobile Phase (68:32) & 2874689 & 14658 & 2884932 & 914 \\
\hline & Mobile Phase (68:32) & 2903977 & 0.51 & 2883254 & 0.03 \\
\hline \multirow[t]{3}{*}{4} & Mobile Phase (72:28) & 2418287 & 2418663 & 2454632 & 2453493 \\
\hline & Mobile Phase (72:28) & 2412354 & 6506 & 2454301 & 1694 \\
\hline & Mobile Phase (72:28) & 2425349 & 0.27 & 2451547 & 0.07 \\
\hline
\end{tabular}

Table 3: Result of Robustness Method.

*Mean of three replicates. 


\section{Forced degradation studies}

In this present study, Finerenone was subjected to a degradation process in thermal, oxidative and photolytic conditions whereas mild degradation was observed in Acidic and alkaline conditions when it was treated with $0.1 \mathrm{~N}$ solution. Degradation of Finerenone in thermal, oxidative and photolytic condition may be due to dihydropyridine property of the racemate mixture.

Finerenone was exposed to acidic and basic conditions and revealed the stability of the drug in this condition and its liability. Increasing the molar concentration of acidic and basic reagents to $1 \mathrm{~N}$, it degrades the drug by around $17 \%$ in both cases which is more than that of $0.1 \mathrm{~N}$ Solutions. Hence, the degradation rate of Finerenone in acidic conditions is equivalent to that in alkali conditions.

At $0.1 \mathrm{~N}$ solutions, the same pattern of degradation was observed for Finerenone in acidic, basic, oxidative, photolytic and thermal conditions. $24 \mathrm{~h}$ exposure of drug in photolytic and thermal conditions degrades the drug to the maximum but within the allotted limit as per the ICH guidelines.

Gradient degradation occurred in Finerenone with increasing reagents molarity, stress conditions and exposure period observed in our proposed method. Data collected during various stress conditions is summarized in table 4 and also the chromatograph of Finerenone in forced degradation condition in figure 5 . The developed methods withstand the stress conditions and proved that this method can be utilized to study and identify the degraded products of Finerenone. Peak purity clearly proved that there is no interference of degradants in finerenone retention time under any stress conditions.

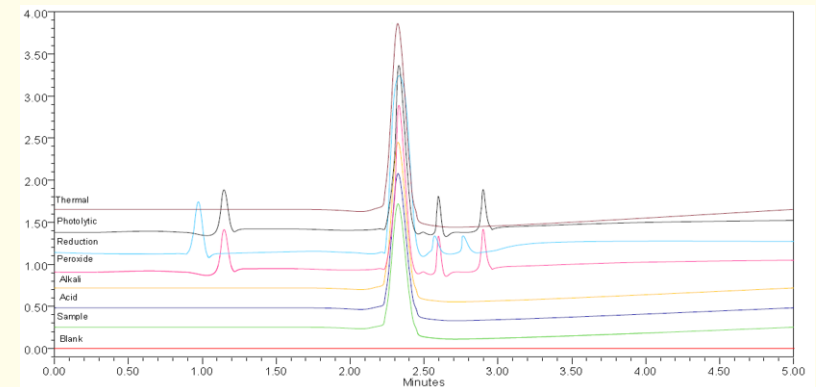

Figure 5: Chromatogram of Finerenone in Photolytic degradation A-Blank, B-Standard, C-Acidic, D-Alkaline, E-Oxidative, F- Thermal, G-Photolytic degradation.

\begin{tabular}{|l|c|c|c|c|c|}
\hline $\begin{array}{l}\text { Stress } \\
\text { Condition } \\
\mathbf{0 . 1 N})\end{array}$ & $\begin{array}{c}* \text { Mean } \\
\text { peak } \\
\text { area }\end{array}$ & $\begin{array}{c}* \text { Drug } \\
\text { recovered } \\
\text { (\%) }\end{array}$ & $\begin{array}{c}\text { *Drug } \\
\text { decom- } \\
\text { posed (\%) }\end{array}$ & $\begin{array}{c}\text { Theo- } \\
\text { retical } \\
\text { plate }\end{array}$ & $\begin{array}{c}\text { Tailing } \\
\text { factor }\end{array}$ \\
\hline $\begin{array}{l}\text { Standard } \\
\text { drug(untreated) }\end{array}$ & 2619472 & 100 & - & 5418 & 1.020 \\
\hline $\begin{array}{l}\text { Acidic } \\
\text { degradation }\end{array}$ & 2589861 & 98.87 & 1.13 & 5888 & 1.060 \\
\hline $\begin{array}{l}\text { Alkaline } \\
\text { degradation }\end{array}$ & 2569741 & 98.10 & 1.90 & 5384 & 1.050 \\
\hline $\begin{array}{l}\text { Oxidative } \\
\text { degradation }\end{array}$ & 2489412 & 95.03 & 4.97 & 5284 & 1.050 \\
\hline $\begin{array}{l}\text { Thermal } \\
\text { degradation }\end{array}$ & 2478475 & 94.62 & 5.38 & 5784 & 1.050 \\
\hline $\begin{array}{l}\text { Photolytic } \\
\text { degradation }\end{array}$ & 2519472 & 96.18 & 3.82 & 5784 & 1.050 \\
\hline
\end{tabular}

Stress Condition (1N)

\begin{tabular}{|l|c|c|c|c|c|}
\hline $\begin{array}{l}\text { Standard } \\
\text { drug(untreated) }\end{array}$ & 2619472 & 100 & - & 5416 & 1.020 \\
\hline Acidic & 2159647 & 82.45 & 17.55 & 5584 & 1.060 \\
\hline degradation & 2151572 & 82.14 & 17.86 & 5674 & 1.050 \\
\hline $\begin{array}{l}\text { Alkaline } \\
\text { degradation }\end{array}$ & 2132553 & 81.41 & 18.59 & 5164 & 1.050 \\
\hline $\begin{array}{l}\text { Oxidative } \\
\text { degradation } \\
(30 \%)\end{array}$ & 2154796 & 82.26 & 17.74 & 5776 & 1.080 \\
\hline $\begin{array}{l}\text { Thermal } \\
\text { degradation } \\
(30 \%)\end{array}$ & 2184736 & 83.40 & 16.60 & 5245 & 1.050 \\
\hline $\begin{array}{l}\text { Photolytic } \\
\text { degradation } \\
(30 \%)\end{array}$ & & & & \\
\hline
\end{tabular}

Table 4: Data of Stress degradation studies Finerenone.

*Mean of three replicates.

\section{Conclusion}

The stability indicating method developed was found to be highly precise, accurate, specific, robust and linear towards its concentration $1-50 \mu \mathrm{g} / \mathrm{Ml}$ at the same time it remains first RP-HPLC as per our knowledge. There were no variations observed in forced degradation studies under acidic, alkaline, oxidative, photolytic and thermal conditions. The proposed method was found to be simpler, specific, reproducible and highly stable. Developed method has the 
ability to identify the degraded products in API and finished formulations of Finerenone. Proposed method is highly recommended to separate, identify and to study stress degradation of Finerenone.

\section{Acknowledgment}

The Author would like to acknowledge the laboratories support provided by Anjuman-I-Islam School of Pharmacy, New Panvel.

\section{Conflict of Interest}

The Author would like to inform NO CONFLICT of interest for our proposed method.

\section{Bibliography}

1. https://www.accessdata.fda.gov/drugsatfda_docs/ label/2021/215341s000lbl.pdf

2. Peter Kolkhof and Lars Barfacker. "Mineralocorticoid receptors: 60 years of research and development". Journal of Endocrinology 234 (2017): T125-140.

3. Juan Simon Rico-Mesa., et al. "Mineralocorticoid Receptor Antagonists: A Comprehensive Review of Finerenone". Current Cardiology Reports 22 (2020): 140.

4. Kolkhof P., et al. "Nonsteroidal antagonists of the mineralocorticoid receptor". Current opinion in Nephrology and Hypertension 24.5 (2015): 417-424.

5. Kolkhof P., et al. "Finerenone, a novel selective non-steroidal mineralocorticoid receptor antagonist protects from rat cardio renal injury". Journal of Cardiovascular Pharmacology (2014).

6. Gabriele Rohde., et al. "Determination of finerenone - a novel, selective, nonsteroidal mineralocorticoid receptor antagonist - in human plasma by high-performance liquid chromatography-tandem mass spectrometry and its application to a pharmacokinetic study in venous and capillary human plasma". Journal of Chromatography B 1172 (2021): 122643.

7. Bose. "HPLC calibration process parameters in terms of system suitability test". Austin Chromatography 1.2 (2014).

8. USP - The United States Pharmacopeia and National Formulary USP 42 NF37, The United States Pharmacopoeial Convention, Inc.: Rockville, MD (2019).

9. ICH - International Council of Harmonization. "Stability testing of New Drug Substances and Products - Q1A (R2)” (2003).
10. ICH Harmonised Tripartite Guideline, Stability Testing: Photostability Testing of New Drug Substances and Products, Q1B, 1996 (2020).

11. ICH Harmonised Tripartite Guideline Validation of analytical procedures: text and methodology Q2 (R1), in: Validation of Compendia Procedures USP 40 - NF 35, (Chapter 1225) (2005): 1780-1783.

\section{Volume 5 Issue 12 December 2021}

(C) All rights are reserved by Arulselvan Murugesan and Annapurna Mukthinuthalapati Mathrusri. 